\title{
Superexploração da força de trabalho e saúde do trabalhador: o trabalho precário na confecção
}

\author{
I 1 Paulo Victor Rodrigues de Azevedo Lira, ${ }^{2}$ Idê Gomes Dantas Gurgel, \\ ${ }^{3}$ Angela Santana do Amaral I
}

Resumo: É essencial o entendimento das mudanças ocorridas no mundo do trabalho e de como estas se relacionam com o processo saúde-doença. Objetivouse analisar as expressôes da superexploração da força de trabalho e sua repercussão na saúde dos trabalhadores de facçôes instaladas em dois municípios do arranjo produtivo local de confecçóes do Agreste pernambucano. A pesquisa foi orientada por uma perspectiva que considera a totalidade e a historicidade das relações sociais e sua articulação com os processos sociais particulares. Foram aplicados questionários e entrevistas semiestruturadas para trabalhadores da confecção dos municípios de Toritama e Santa Cruz do Capibaribe, no ano de 2017. Os resultados foram analisados com base no método dialético. A superexploração da força de trabalho se expressou nas relaçóes de trabalho por meio da articulação da remuneraçáo da força de trabalho abaixo de seu valor, do aumento do valor histórico moral da força de trabalho sem seu pagamento correspondente, da extensão das jornadas de trabalho e da intensificação do trabalho exercido nas facções. Tais características tendem a violar o fundo de consumo e de vida dos trabalhadores, que poderão apresentar um desgaste precoce de sua força de trabalho, podendo ser evidenciado pelo adoecimento e/ou perda precoce da capacidade para o trabalho.

> Palavras-chave: saúde do trabalhador; precarização do trabalho; doenças relacionadas ao trabalho.

\author{
' Fundação Oswaldo Cruz, Instituto \\ Aggeu Magalhães. Recife-PE, Brasil \\ (paulo.alira@gmail.com). \\ ORCID: 0000-0002-8588-839X \\ ${ }^{2}$ Fundação Oswaldo Cruz, Instituto \\ Aggeu Magalhães. Recife-PE, Brasil \\ (ideg@cpqam.fiocruz.br). \\ ORCID: 0000-0002-2958-683X \\ ${ }^{3}$ Universidade Federal de \\ Pernambuco. Recife-PE, Brasil \\ (angelaufpe@yahoo.com.br). \\ ORCID: 0000-0003-2038-1296
}

Recebido em: 19/04/2019 Aprovado em: 15/07/2019 Revisado em: 17/02/2020 


\section{Introdução}

A partir da compreensão do "campo" saúde do trabalhador, é essencial o entendimento das mudanças ocorridas no mundo do trabalho e de como estas relacionam-se com o processo saúde-doença. A dinâmica de reorganização/ reestruturação produtiva expressa-se em inúmeros processos nacionalmente. Dentre eles, encontram-se as mudanças na indústria têxtil e de confecçôes, com extenso enxugamento da força de trabalho nas fábricas, desterritorialização da produção com a terceirização e/ou subcontrataçôes de unidades produtivas menores via contratação de cooperativas, empreendimentos informais, as chamadas facçóes ${ }^{1}$, e uso do trabalho domiciliar (JINKINGS; AMORIM, 2006; CABREIRA; WOLFF, 2013).

As mudanças ocorridas não são particularidades do trabalho na confecção, como analisam Abramides e Cabral (2003), que alertam para os problemas de saúde ocasionados pelo processo de reestruturação produtiva, como a crescente incidência de lesóes por esforço repetitivo (LER), distúrbios osteomusculares relacionados ao trabalho (DORT) e transtornos mentais causados pela forma de organização do trabalho, pela instabilidade, pela perda de direitos trabalhistas, pelo aumento da intensidade, e pela terceirização e quarteirização. A relação entre intensificação do trabalho, aumento das jornadas e a diminuição dos salários, ocorrendo simultaneamente ou não, influencia diretamente na saúde dos trabalhadores e expressa uma condição de superexploração da força de trabalho (LUCE, 2012). A constituição do chamado "Polo de Confecçôes do Agreste" está inserida nesta dinâmica.

Observou-se, entre os anos 1980 e 1990, o crescimento de atividades relacionadas à produção de confecçóes no Arranjo Produtivo Local (APL) do Agreste de Pernambuco, conhecido popularmente como "Polo de Confecçôes", cuja finalidade inicial era a produção de mercadorias, de menor qualidade, para o comércio regional. Ao longo do tempo, a produção foi se diversificando e aumentando a sua abrangência territorial (LIRA, 2006).

Em 2003, o setor gerou 76 mil empregos, e eram estimadas 12 mil micro e pequenas indústrias na região, com faturamento anual de dois bilhóes de reais, ocupando a segunda posição nacional na produção de confecçôes, apesar de estar apenas na quinta posição na geração de empregos formais (ARAUJO; PEREIRA, 2006; AMARAL; MACEDO, 2011). Já em 2012, eram mais de 100 mil pessoas 
envolvidas no processo de produção, com destaque para a alta informalidade (SEBRAE, 2013; CARVALHO; SILVA, 2015).

O processo desenvolvido no APL de confecçóes seguiu as mudanças que vinham ocorrendo no mundo do trabalho, caracterizado pelo pagamento de baixos salários, aumento da intensidade do trabalho associado ao prolongamento das jornadas, enfraquecimento dos sindicatos, subcontratação, terceirização, diminuição dos encargos sociais, descentralização da produção, fragmentação do processo produtivo através da estratégia de formação de APL. Cerca de 80\% das unidades de produção dos municípios que compõem o tripé do APL de confecçóes (Caruaru, Toritama e Santa Cruz do Capibaribe) eram informais (MACEDO; AMARAL, 2013; SEBRAE, 2013).

Essas unidades produtivas executam serviço de corte, costura, bordado, acabamento, entre outras fases do processo de produção, com a remuneração, na maioria das vezes, sendo realizada por peça produzida. Além das cargas de trabalho inerentes ao processo na confecção, as mudanças no mundo do trabalho promovem a insegurança nos trabalhadores, seja pela ameaça do desemprego, seja por estarem desempregados ou em atividades extremamente precárias (DRUCK, 2011; 2012; AMARAL, 2018). Essas alteraçóes podem se expressar ou não no adoecimento dos trabalhadores, mas são condiçóes determinantes para o desgaste biopsíquico destes (LAURELL; NORIEGA, 1989).

A saúde do trabalhador como um "campo" em permanente construção (MINAYO-GOMEZ; THEDIM-COSTA, 1997) aponta a necessidade de analisar e compreender as mudanças e seus impactos na saúde da classe trabalhadora para que se possa subsidiar a construção de políticas públicas. Além de aprofundar o debate da "questão" da saúde dos trabalhadores que transcende o próprio "campo" saúde do trabalhador (SOUZA; MELO; VASCONCELLOS, 2017).

Tendo em vista o processo de precarização social do trabalho, o presente artigo tem como objetivo analisar as expressôes da superexploração da força de trabalho em trabalhadores de facçóes instaladas em dois municípios do APL de Confecçôes do Agreste Pernambucano.

\section{Método e percurso metodológico}

A pesquisa foi orientada por uma perspectiva que considera a totalidade e a historicidade das relaçóes sociais e sua articulação com os processos sociais particulares, 
compreendendo a realidade concreta como síntese de múltiplas determinaçôes (KOSIK, 1976). Trata-se de estudo de natureza descritiva e exploratória, baseado em abordagem quantitativa e qualitativa, e desenvolveu-se nos anos de 2017 e 2018 nos municípios de Toritama e Santa Cruz do Capibaribe, localizados na regiáo Agreste do Estado de Pernambuco.

Para definição da amostra, nos baseamos no conceito de sítio/população sentinela caracterizado por Samaja (1996). Foram aplicados 37 questionários, sendo 23 em Toritama e 14 em Santa Cruz do Capibaribe, e realizadas 14 entrevistas semiestruturadas, nove em Toritama e cinco em Santa Cruz do Capibaribe. O questionário aplicado continha 61 questóes e estava organizado em três eixos prioritários: 1) perfil do trabalhador (ex. nome, faixa etária, escolaridade); 2) aspectos sociais e de trabalho (ex. trabalho registrado, remuneração, jornada de trabalho, quantitativo de peças produzidas); e 3) aspectos relacionados à saúde (ex. queixas de saúde, "riscos" presentes no ambiente de trabalho, acidentes de trabalho, afastamento do trabalho).

Os questionários foram aplicados pela equipe da pesquisa no ano de 2017. A aplicação foi no local de trabalho, em sua maioria facçôes, mediante o consentimento do(a) trabalhador(a) em responder à pesquisa.

As entrevistas semiestruturadas foram realizadas com trabalhadores(as) diferentes dos que haviam respondido aos questionários. Este tipo de entrevista estimula os sujeitos a falarem mais sobre o tema, possibilitando obter um maior número de informações dos entrevistados. (SANTOS; OSTERNE; ALMEIDA, 2014). As entrevistas seguiram um roteiro preestabelecido. Este foi baseado nos critérios observados para construção do questionário e na enquete operária formulada por Marx em 1880, que leva em consideraçáo aspectos relativos à jornada e à intensidade do trabalho, acidentes de trabalho e condiçôes de vida dos trabalhadores (ALVES; JACKSON FILHO, 2017). Os entrevistados foram identificados pela letra "S" (sujeito), pelo número da entrevista realizada, seguido do nome do município.

Os dados dos questionários foram digitados e tabulados utilizando o programa Excel $^{\triangleright}$ 2013. Os dados dos roteiros de entrevistas semiestruturadas foram gravados e transcritos na íntegra e armazenados em banco com o pesquisador. A análise dos dados foi realizada de acordo com o método dialético. Foram consideradas as categorias superexploração da força de trabalho, determinação social da saúde, reprodução social, processo de trabalho e jornada de trabalho como categorias 
essenciais para compreender a estrutura e a dinâmica do processo saúde-doença dos trabalhadores das facções. Os conceitos de precarização, intensificação, cargas de trabalho e desgaste do trabalhador também foram importantes mediadores teóricos da análise.

Este artigo é parte da dissertação de mestrado $A$ determinação social da saúde dos(as) trabalhadores(as) da confeç̧ão do Agreste pernambucano: desgaste e adoecimento como expressáo da superexploração da força de trabalho, com parecer aprovado no Comitê de Ética em Pesquisa com Seres Humanos do Instituto Aggeu Magalhães (IAM), com Certificado de Aprovação para Apreciação Ética (CAAE) número 73417817.5.0000.5190.

\section{Resultados e Discussão}

\section{A superexploração da força de trabalho nos municípios de Toritama e Santa Cruz do Capibaribe}

A superexploração da força de trabalho é realizada como mecanismo de compensação da dinâmica desigual constituída historicamente entre periferia e centro do capitalismo, como forma de contra-arrestar os valores transferidos da periferia para o centro (MARINI, 2011). O desenvolvimento do modo de produção capitalista nos países dependentes não é isolado da dinâmica global, articula-se com ela, sendo o subdesenvolvimento característica fundamental para o desenvolvimento presente nos países de capitalismo central (MARINI, 2011; LUCE, 2012; 2013; 2018). Portanto, o capitalismo dependente é "regido" por leis tendenciais particulares "como são a transferência de valor como intercâmbio desigual, a cisão nas fases do ciclo do capital e a superexploração da força de trabalho, que se cristalizaram enquanto características [...] em nossas sociedades" (LUCE, 2018, p. 162). A partir desta particularidade, analisamos a superexploração da força de trabalho e suas formas de expressão no trabalho desenvolvido nas facções.

As formas de expressão da superexploração da força de trabalho são expostas na figura 1. 
Figura 1. Formas de expressão da superexploração da força de trabalho

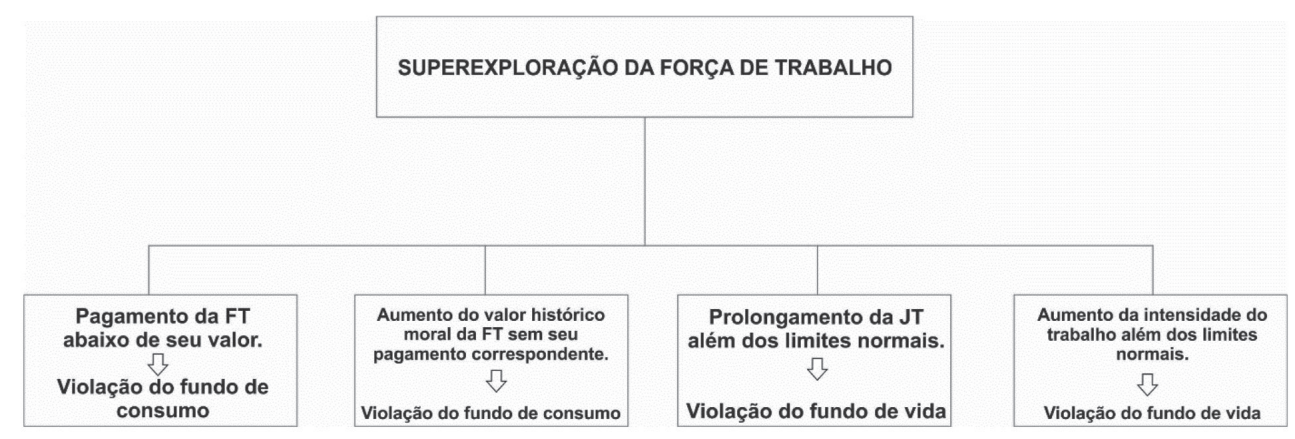

Fonte: adaptado de Luce (2018).

\section{O pagamento da força de trabalho abaixo de seu valor}

Antes de iniciarmos a nossa análise, é fundamental explicitar como o valor da força de trabalho é definido. Segundo Marx:

O valor da força de trabalho, como o de todas as outras mercadorias, é determinado pelo tempo de trabalho necessário para a produção - e, consequentemente, também para a reprodução - deste artigo específico. Como valor, a força de trabalho representa apenas uma quantidade de trabalho social médio nela objetivado. [...] Para sua manutenção, o indivíduo vivo necessita de certa quantidade de meios de subsistência, ou, dito de outro modo, o valor da força de trabalho é o valor dos meios de subsistência necessários à manutenção de seu possuidor [...] O valor da força de trabalho se reduz ao valor de uma quantidade determinada de meios de subsistência e varia [...] de acordo com a magnitude do tempo de trabalho requerido para sua produção (MARX, 2013, p. 245-247).

O que Marx explicita é a necessidade que a força de trabalho tem de receber certa quantia de meios de subsistência, como alimentação, moradia, educação, vestuário, lazer, entre outras, para que seja garantida sua reprodução. Esta quantia é determinada historicamente, assim, o elemento histórico moral é considerado na atribuição do valor desta mercadoria específica (MARX, 2013). Dito isto, passemos a análise nos municípios estudados.

Em relação à renda dos trabalhadores, observamos que $67,57 \%$ (25) dos entrevistados recebem até um salário mínimo, com 21,62\% (8) destes recebendo menos que um salário. ${ }^{2}$ Os outros $27,03 \%$ receberam em torno de um a dois salários mínimos, o que acarretaria no máximo uma renda de $\mathrm{R} \$ 1.874,00$. Ainda é necessário reforçar que os entrevistados se encontram na informalidade, logo estão 
em um acentuado estado de desproteção social, sobretudo em relação a direitos trabalhistas e previdenciários. Também é necessário ressaltar que 73,78\% dos entrevistados possuíam na data da entrevista pelo menos um dependente.

É possível realizar a comparação entre a renda dos trabalhadores entrevistados e o Salário Mínimo Necessário (SMN) 3 calculado pelo DIEESE (2018). Este último sofreu variaçôes nos meses em que a pesquisa foi realizada, estando entre $\mathrm{R} \$ 3.658,72$ e 3.899,66, com média de $\mathrm{R} \$ 3.782,74$. Portanto, o SMN seria o valor mínimo que atenderia às necessidades de reprodução da força de trabalho, considerando seus aspectos fisiológicos e histórico-morais. A discrepância é explicitada na comparação entre o salário mínimo nominal e o SMN, que apresenta um valor quatro vezes mais alto que o primeiro. Destarte, o que identificamos nos municípios estudados é o distanciamento entre o salário recebido pelos trabalhadores e o SMN, em que nenhum trabalhador entrevistado recebe uma quantia próxima à estabelecida pelo DIEESE.

A violação do valor da força de trabalho, expressa na remuneração da força de trabalho abaixo de seu valor, expóe a condição de superexploração da força de trabalho a que os trabalhadores estão submetidos nas facçôes. A condição aparece também nos relatos dos entrevistados ao abordarem a renda insuficiente para suprir necessidades básicas:

[...] na verdade acaba faltando tudo [...] A casa é alugada. Aí, quando pago o aluguel atrasa
a conta de luz, aí vai segurando como pode. É uma água que tem que comprar, tanto para
as atividades domésticas, como para beber, tudo tem que comprar. [quando está faltando
alimentaçáo] aí vai na casa do pai dela e da mãe dela e diz assim: olha, tá faltando arroz,
tá faltando carne [...] aí a mãe dela vai e ajuda. (S2 Toritama).

Também é reforçado o papel das políticas assistenciais, como o programa Bolsa Família:

Sempre falta dinheiro. Ainda bem que tem a ajuda do Bolsa Família, porque como as coisas estáo fracas, aí tira dinheiro pra uma coisa, aí tira pra outra, quando chega no final do mês que você vem somar, aí fica uma coisa para pagar (S2 Santa Cruz do Capibaribe).

O benefício cumpre assim com o papel de complementar as necessidades básicas dos trabalhadores, atuando no auxílio à reprodução da força de trabalho nas facçôes. Rodrigues (2010), além de constatar esta relação entre o recebimento do benefício e a reprodução da força de trabalho, abordou o papel que este teve no rebaixamento dos salários dos trabalhadores de facçóes em Toritama. 
Os principais gastos para a reprodução da força de trabalho foram relatados pelos entrevistados, expressos em: alimentação (78\%); luz e água (70,27\%); aluguel (19\%); lazer e gastos com a saúde com o mesmo percentual de 11\%. Além dos gastos principais para a reprodução da força de trabalho, também é evidente a tendência da produção flexível do APL, que externaliza o processo de produção das mercadorias e assim seus custos para os trabalhadores. Essa tendência é observada nas atuais mudanças no mundo do trabalho, expressas de diferentes formas, mas mantendo seu conteúdo de externalização e responsabilização dos trabalhadores pela sua formação e custos do processo produtivo (AMARAL, 2018).

A relação "empreendedora" evidencia suas contradições, e os salários também são utilizados para custear a produção: no pagamento de energia elétrica; na compra e manutenção de equipamentos; na organização do ambiente de trabalho; no pagamento de aluguel e, em alguns casos, no pagamento por produçáo aos trabalhadores contratados. Esta "confusão" entre domicílio e local de trabalho possibilita a conversão do fundo de consumo do trabalhador em fundo para acumulação capitalista. Além disso, o gasto mais elevado com o consumo de água, por meio da compra em caminhôes-pipa, e o custeamento de serviços privados de saúde indicam também a transferência do fundo de consumo do trabalhador para a acumulação capitalista. Como analisam Mota e Peruzzo (2015, p. 9):

[...] as expropriaçôes de direitos, paralelamente à oferta de serviços mercantis antes acessados como políticas públicas, podem ser consideradas mecanismos de superexploração do trabalho, porquanto uma parcela do salário/remuneraçáo do trabalhador destina-se à compra de bens e serviços - como saúde, educação, creches, lazer, cultura etc. [...] Ou seja, formas evidentes de superexploração, a contrataçáo do trabalhador por baixo do valor da força de trabalho - ou a conversão de parcela do fundo de consumo do trabalhador em fundo de acumulação do capital.

Outra condição determinante para a remuneração abaixo do seu valor é a expressa na quantidade de trabalhadores disponíveis para execução de atividades na regiáo, que depende quase que exclusivamente da produção de confecçôes. A constituição de um grande contingente de trabalhadores na superpopulação relativa, em ocupaçóes estagnadas, porém produtivas para o capital, favorece a redução dos salários sem maiores repercussôes: “[...] já tem um valor fixo. Trabalho com ele há três anos. Quando ameaçamos alterar o valor da peça ele já procura outra facção e já coloca em outro lugar" (S2 Toritama). Além disso, a organização coletiva dos trabalhadores é frágil: 89,19\% (33) dos entrevistados desconhecem a existência de 
sindicatos e/ou associaçôes de costureiros e os 10,81\% (4) que dizem conhecer nunca participaram de nenhum espaço da entidade. Como explicita Dal Rosso (2011, p. 142): "Entre as razóes declaradas do deslocamento de empresas do centro a periferia estão a mão de obra barata e a sua não organização política, ainda, em sindicatos e movimentos, bem como a fuga de regiôes em que estas organizaçôes são fortes".

Configuram-se assim os mecanismos que possibilitam a remuneração da força de trabalho abaixo de seu valor, dos quais destacamos: 1) processo produtivo ser baseado na informalidade; 2) presença de um grande contingente de trabalhadores disponíveis para a atividade; 3) atuação do Estado contribuindo com a reprodução da força de trabalho; 4) externalização dos gastos da produção para os trabalhadores; 5) baixa participação dos trabalhadores na esfera de circulação (na realização) de mercadorias; e 6) deficiência na organização coletiva dos trabalhadores.

Evidentemente, expomos esses mecanismos como determinaçóes impostas pela própria lógica do capitalismo dependente. Dessa forma, não incorremos no "idealismo" de superação da lógica presente no APL por medidas mitigantes que acabam por estimular uma "informalidade formalizada". A contradição é expressa pela diferença entre o faturamento do APL e a remuneração abaixo de seu valor recebida pelos trabalhadores. Notícias divulgadas por grandes veículos da mídia do estado apontam que o "Polo de Confecçôes" se destaca nacionalmente como o segundo maior no segmento, atrás apenas do Polo de Confecçóes Paulista (LACERDA, 2013; JC ONLINE, 2017; PIMENTEL, 2017). Ainda segundo Pimentel (2017), somente o município de Santa Cruz do Capibaribe é responsável pela produção de 30\% das confecçóes do Polo, o que corresponde a 2,4 bilhôes de reais por ano do produto interno bruto (PIB) de Pernambuco. A participação do Agreste no PIB do estado passou de 14,1\%, equivalente a 14,6 bilhóes de reais, para $15,7 \%$, equivalente a 24,3 bilhóes de reais (JC ONLINE, 2017). Apesar disso, o que encontramos nas respostas dos entrevistados são condiçóes flexíveis e precárias de trabalho sendo remuneradas abaixo de seu valor.

A remuneração da força de trabalho abaixo de seu valor não é uma expressão isolada dos trabalhadores de facçôes nos municípios estudados, é uma tendência presente em nosso país. Dados da PNAD 2017 acerca do rendimento médio mensal real de todos os trabalhos apontam para um valor nacionalmente de $\mathrm{R} \$ 2.178,00$, com diferenças em relação ao sexo: as mulheres receberam em média $\mathrm{R} \$ 1.868,00$, 
em torno de $22 \%$ a menos do que os homens que recebiam, R\$2.410,00. Quando os dados são organizados por região geográfica, o Nordeste apresenta valor de rendimento médio de $\mathrm{R} \$ 1.509,00$, com as mulheres recebendo em torno de $\mathrm{R} \$$ $1.362,00$ e os homens, $\mathrm{R} \$ 1.612,00$ (IBGE, 2018). Já ao considerarmos o rendimento médio dos $50 \%$ da população com os menores rendimentos, a pesquisa aponta uma média nacional de R \$754,00, ou seja, menos que um salário mínimo nominal. Quando o dado é restringido à Região Nordeste, o valor chega a R \$ 487,00 (IBGE, 2018). Os dados só reforçam a constatação de que a classe trabalhadora brasileira se encontra sob o jugo da superexploração da força de trabalho, tendo seu fundo de consumo violado e, consequentemente, esta violação também incidirá sobre o fundo de vida destes trabalhadores. Como ressalta Luce (2013, p. 176): "Se o salário não alcança quantia suficiente para o trabalhador repor o desgaste de sua força de trabalho, estaremos diante da superexploração".

Por fim, ressaltamos uma condição que pode derivar da remuneração da força de trabalho abaixo de seu valor, mas que tem outros determinantes históricos. O valor da força de trabalho é histórico-moral, ou seja, é fruto de múltiplas determinaçôes que estão associadas a questôes econômicas, culturais, políticas, entre outras. Com o desenvolvimento do modo de produção capitalista, novas necessidades de consumo são geradas. Um exemplo simples disto é que grande parte da população brasileira tem acesso a bens de consumo que há 50 anos eram restritos a parcelas específicas da sociedade, como a televisão, além da necessidade de novas mercadorias como o celular e a internet, esta última ainda mais restrita. Esse exemplo explicita um aumento no elemento histórico-moral da força de trabalho.

No entanto, como expôe Luce (2012; 2013; 2018), essa elevação não é acompanhada pela elevação da remuneração recebida pelos trabalhadores. Restam ao trabalhador três opçóes: 1) o endividamento; 2) o aumento da jornada de trabalho para custear as dívidas; e 3) o aumento da intensidade do trabalho para custear as dívidas. $\mathrm{O}$ autor demonstrou que essa tendência atuou na chamada "classe $\mathrm{C}$ "’, que foi responsável por 45\% das compras de eletrodomésticos no ano de 2010, e em 2012 correspondia a mais de $50 \%$ das famílias inadimplentes.

Os gastos relatados pelos entrevistados em ambos municípios são mais relacionados a bens prioritários para a reprodução da força de trabalho, como alimentação, moradia, energia e água. Porém, as novas necessidades aparecem no relato: 


\begin{abstract}
Hoje o lucro tá pouquinho demais. Porque a energia aumentou. Dá para pagar as contas. E tem mês que já passa apertado, uma coisa... porque a gente usa o serviço de internet também, aí tem que ter, hoje em dia tem que ter, porque é um meio de comunicação muito bom. Aí isso aí já aumenta no orçamento (S4 Toritama).
\end{abstract}

\title{
O prolongamento da jornada de trabalho além de seus limites normais
}

As jornadas de trabalho desenvolvidas nas facções são relativas, dependem do quantitativo de encomendas realizadas, variando em diferentes meses dos anos. Malgrado esta importante observaçáo, o prolongamento das jornadas acima das oito horas diárias é uma característica da produção para a maior parte dos trabalhadores entrevistados em qualquer época do ano. Os meses que antecedem os períodos festivos, como são-joão e Natal, são aqueles em que os trabalhadores se submetem às maiores jornadas de trabalho.

$\mathrm{O}$ aspecto qualitativo da jornada de trabalho é expresso em uma distribuição desigual das jornadas durante o ano. Nos meses de alta produção, quando relacionados aos períodos de baixa produtividade, ocorre uma variação na jornada de 77\% em Toritama e 75\% em Santa Cruz do Capibaribe, se considerarmos o limite de oito horas diárias. Ou seja, dos trabalhadores que relataram trabalhar até oito horas nos períodos de produção normal/baixa, 77\% e 75\% têm que elevar suas jornadas para além das oito horas diárias nos períodos de pico produtivo. Ainda considerando o período de pico produtivo, 64\% dos entrevistados em Santa Cruz do Capibaribe e $52 \%$ em Toritama afirmam trabalhar mais de 12 horas diárias, totalizando no mínimo 60 horas semanais (sem contabilizar as horas trabalhadas aos sábados e domingos).

Em nosso estudo, o "processo de informalidade" associado ao pagamento do salário por peça, este sendo inferior às necessidades de reprodução da força de trabalho, é o elemento determinante para a extensão das jornadas para além dos seus limites normais. A ausência de regulação e o desenvolvimento do processo de trabalho no domicílio ou próximo deste favorecem o prolongamento desta jornada. O alongamento da jornada também se materializa nos trabalhos aos fins de semana, feriados e na ausência de férias regulares. Em torno de 68\% (25) dos entrevistados relatam trabalhar aos fins de semana, associado a isto, $62 \%$ (23) afirmam não tirarem férias durante o ano. Os períodos de descanso ficam restritos à época do ano em que a produção está baixa e a recessos como o período de carnaval e ano-novo. No relato 
é possível extrair elementos que materializam o esgotamento dos trabalhadores por meio da extensão das jornadas:

[...] eu já cheguei a passar mal de tanto que eu costurei, sem dormir direito. Eu cheguei a desmaiar. Eu desmaiei porque eu estava sem conseguir dormir, muitos dias fazendo serão até tarde e amanhecendo o dia praticamente. Aí uma hora, duas horas da manhã, ficou muito. Fiquei muito cansada (S4 Santa Cruz do Capibaribe).

Acerca da extensão das jornadas de trabalho, Luce (2018) acompanhou tendência histórica, em diferentes períodos, comparando sua duração em países de capitalismo central e em países de capitalismo periférico latino-americanos. O que o autor constata é que a média de duração da jornada de trabalho é maior nos países de capitalismo dependente do que nos países de capitalismo central. A característica não é mera arbitrariedade, é fruto da necessidade de ampliação da taxa de maisvalia, baseada na extração da mais-valia absoluta, com a finalidade de compensar as perdas oriundas da relaçáo diferenciada de produção e apropriação do valor.

Ressaltamos, entretanto, que a superexploração da força de trabalho não pode ser confundida como sinônimo de extração de mais-valia absoluta. Na primeira, a extensão da jornada de trabalho acima dos limites normais tem duração suficiente para atentar contra o fundo de vida dos trabalhadores. Para explicar esta relação, é necessário compreender as categoriais mediadoras de valor diário da força de trabalho, seu valor total e a relação com a extensão da jornada de trabalho. Marx analisa:

Por meio de um prolongamento desmedido da jornada de trabalho, podes, em um dia, fazer fluir uma quantidade de minha força de trabalho maior do que a que posso repor em três dias. O que assim ganhas em trabalho eu perco em substância do trabalho. A utilização de minha força de trabalho e o roubo dessa força são coisas completamente distintas. Se o período médio que um trabalhador médio pode viver executando uma quantidade razoável de trabalho é de 30 anos, o valor de minha força de trabalho, que me pagas diariamente, é de $1 / 365 \times 30$, ou $1 / 10.950$ de seu valor total. Mas se a consomes em 10 anos, pagas-me diariamente $1 / 10.950$ em vez de 1/3.650 de seu valor total; portanto, apenas $1 / 3$ de seu valor diário, e me furtas, assim, diariamente, $2 / 3$ do valor de minha mercadoria. Pagas-me pela força de trabalho de um dia, mas consomes a de 3 dias (MARX, 2013, p. 308).

Assim, a extensão da jornada de trabalho não se relaciona apenas com seu desenvolvimento imediato, materializado na duração da jornada e em seu valor pago diariamente. O prolongamento da jornada influenciará no consumo da força de trabalho ao longo do tempo, esgotando-a precocemente, reduzindo seu valor total e violando o fundo de vida dos trabalhadores (LUCE, 2013; 2018). 
A respeito disso, Marx conclui:

Assim, a produção capitalista, que é essencialmente produção de mais-valor, sucção de mais-trabalho, produz o prolongamento da jornada de trabalho, não apenas a debilitação da força humana de trabalho, que se vê roubada de suas condiçóes normais, morais e físicas, de desenvolvimento e atuaçáo. Ela produz o esgotamento e a morte prematuros da própria força de trabalho. Ela prolonga o tempo de produção do trabalhador durante certo período mediante o encurtamento de seu tempo de vida (MARX, 2013, p. 338).

A relação entre o prolongamento, em seu aspecto quantitativo e/ou qualitativo, e a saúde dos trabalhadores é analisada por Silva (2013). O autor realiza revisão de estudos e reportagens em diferentes países (Estados Unidos da América, Japão, Alemanha, Brasil, entre outros), constatando a relação entre a ampliação das jornadas e a maior ocorrência de acidentes de trabalho e adoecimento relacionado ao trabalho, inclusive com o desencadeamento de mortes e até mesmo casos de suicídios.

Do total de trabalhadores entrevistados, $27 \%$ (10) relatam ter sofrido ou conhecer algum trabalhador que sofreu acidente de trabalho enquanto costurava. Quando destrinchado por município, 30\% (7) dos entrevistados em Toritama e 21\% (3) informaram ter sofrido acidente ou conhecer alguém que sofreu. A maior parte dos entrevistados relata não ter sofrido acidente, apesar de que em algumas entrevistas se referiam a acidentes considerados por eles como "leves", nos quais a agulha da máquina atingia os dedos das mãos: "Só assim quando alguém machuca o dedo na agulha, né? Às vezes a costura machuca. É só um furinho normal, só é botar remédio e pronto" (S5 Toritama). Um dos entrevistados relatou um caso de trabalho no passado: "Aqui em máquina nunca aconteceu acidente. Só besteira assim. Aonde eu trabalhava, levei uma queda e quebrei o braço. Eu trabalhava de cassaco. Eu caí de uma parede aí quebrei o braço" (S8 Toritama). A ocupação chamada de "cassaco" consiste em auxiliar as atividades das costureiras dentro da facção, geralmente executada por crianças e adolescentes como no caso do relato, em que o entrevistado afirmou ser menor de 18 anos na época do acidente.

A respeito dos acidentes de trabalho ocorridos em território nacional, segundo informações do Anuário Estatístico da Previdência Social, ocorreram no ano de 2016 em torno de 578,9 mil, número 6,58\% mais baixo quando relacionado ao ano anterior (BRASIL, 2016). Porém, cabe ressaltar que os dados são para trabalhadores formalizados, e houve aumento na taxa de desocupação e informalidade nos últimos anos, além da já conhecida subnotificação. Luce (2018) e Silva (2013), ao analisarem séries históricas mais longas, constatam a partir do início do século XXI o incremento 
no número de acidentes e doenças relacionadas ao trabalho. Estes podem relacionarse à extensão das jornadas de trabalho em diferentes setores da economia, como também analisaram os autores.

Dessa maneira, fica evidente que o prolongamento da jornada de trabalho não é exclusividade do trabalho informal. O processo de precarização e flexibilização do trabalho, associado a novas formas de gestão da força de trabalho, e a desregulamentação da legislação trabalhista permitem o avanço dessa condição para os empregos formais. Alguns exemplos que permitem explicitar essa condição estão materializados por meio do banco de horas, horas extras, venda de férias, trabalho aos fins de semana e feriados, negociação da redução do horário de almoço, entre outras (DAL ROSSO, 2017; LUCE, 2018). Afinal:

O capital não tem, por isso, a mínima consideração pela saúde e duração da vida do trabalhador, a menos que seja forçado pela sociedade a ter essa consideração. Às queixas sobre a degradaçáo física e mental, à morte prematura, à tortura do sobretrabalho, ele responde: deveria esse martírio nos martirizar, ele que aumenta nosso gozo? (MARX, 2013, p. 342).

Destarte, o avanço promovido pelo capital não se restringe a um setor produtivo específico, ao contrário, atua de forma distinta e articulada para garantir sua reprodução ampliada. O avanço sobre o tempo livre dos trabalhadores está contido na nova organização do trabalho. Porém, as alteraçôes não se restringem ao prolongamento das jornadas de trabalho. A dinâmica flexível exige dos trabalhadores "polivalência", "capacidade de adaptação" e "superação" (ALVES, 2007; ANTUNES, 2009; DRUCK, 2011). Esta dinâmica também incidirá sobre o desenvolvimento diferenciado do trabalho em dado período fixo de tempo; assim é necessário analisar o processo de intensificação do trabalho.

\section{Aumento da intensidade do trabalho além dos limites normais}

Outra forma de manifestação da superexploração da força de trabalho é o aumento da intensidade do trabalho: "O aumento da intensidade do trabalho aparece, nessa perspectiva, como um aumento da mais-valia, obtido através de uma maior exploração do trabalhador e não do incremento de sua capacidade produtiva” (MARINI, 2011, p. 147). Por consequência, essa condição não é sinônimo do aumento da produtividade do trabalho, esta última está baseada na implantação de tecnologias que reduzam o tempo de trabalho socialmente necessário para sua produção. Já a intensificação do trabalho tem o foco em um maior dispêndio de energias, seja este físico, psíquico el 
ou intelectual por parte dos trabalhadores que executam a função, e tem em seu cerne uma maior exploração da força de trabalho (DAL ROSSO, 2008).

Como destaca Luce (2012), o aumento da intensidade do trabalho e o prolongamento das jornadas de trabalho são características que vêm se agudizando com o processo de reestruturação produtiva. Destarte, o trabalho realizado nas facções também sofre variaçóes em relação à sua intensidade, condicionada, sobretudo, aos períodos onde são realizadas mais encomendas. Segundo o relato da entrevistada:

Eu não paro muito não porque eu tenho que entregar as peças, né?! Eu só paro mesmo quando eu termino. Chega um ponto que tem que parar senão não aguento, eu passo uns minutos, às vezes eu passo uma hora, duas horas [sem trabalhar por dores]. Às vezes eu desisto, paro. Vou e começo no outro dia. Aí é ruim pra mim, né? Porque se eu não entregar, eu não ganho. Se eu entregar 100 peças, só ganho aquelas 100 peças (S3 Toritama).

Outro entrevistado expóe: "se tiver muita entrega a gente almoça na máquina, e na máquina mermo fica” (S2 Santa Cruz do Capibaribe). Dal Rosso (2011) explica que a produção de mais valores na sociabilidade capitalista baseia-se na extensão das jornadas de trabalho, no aumento da intensidade do trabalho e no aumento da produtividade do trabalho. $\mathrm{O}$ autor analisa que a presença e a articulação destas formas se dáo de maneira diferenciada - atreladas ao papel que os países têm na economia mundial, apesar de também considerar o avanço das relaçôes e condiçôes de trabalho precárias para países de capitalismo central - e considera a condição dos países da periferia mais complexa de ser analisada. E a forma de exploração é "organizada com base na mais-valia relativa combinada com diversas formas de mais-valia absoluta” (DAL ROSSO, 2011, p. 142).

Isto posto, o que analisamos nos municípios é uma combinação entre extensão das jornadas de trabalho associada ao aumento da intensidade do trabalho realizado, principalmente durante os períodos em que as facçōes recebem mais peças para serem costuradas, consequentemente exigindo um maior dispêndio de energia dos trabalhadores. Ainda segundo Dal Rosso (2008), as empresas utilizam instrumentos que operam na intensificação do trabalho. $\mathrm{O}$ autor elenca estes instrumentos a partir de atividades econômicas do "setor formal" categorizadas por ele como capitalistas modernas, tradicionais e atividades governamentais. Os instrumentos foram categorizados em: 1) alongamento das jornadas de trabalho; 2) ritmo e velocidade; 3) acúmulo de atividades; 4) polivalência, versatilidade e flexibilidade; e 5) gestão por resultados. 
Os instrumentos identificados anteriormente não podem ser transpostos mecanicamente para o nosso estudo, visto que nossos trabalhadores se encontram em uma condição de informalidade. Porém, é possível relacionar o trabalho realizado nas facçôes com pelo menos dois instrumentos identificados pelo autor, que são: o alongamento das jornadas e o ritmo e velocidade do trabalho. Além dos dois instrumentos citados anteriormente, o acúmulo de atividades e a polivalência são metamorfoseadas, não se caracterizam apenas nas atividades relacionadas à costura das peças, mas essencialmente na combinação, quase simultânea, entre as atividades oriundas do processo de trabalho e as tarefas domésticas. As mulheres são as mais afetadas:

Você tem que tomar conta da casa, cuidar dos filhos, aí você vai para escola de noite, ainda tem que entregar as peças. Tem dia que eu me deito onze horas da noite, meia-noite eu estou pela metade! [relatando o desgaste da rotina] (S1 Toritama)".

Cabe ressaltar que os instrumentos de intensificação se expressam na realidade estudada de maneira particular; porém são expressóes da dinâmica flexível do capitalismo e da necessidade de superexplorar a força de trabalho. Logo, os instrumentos elencados anteriormente sofrem mediação de uma categoria essencial para a compreensão do trabalho nas facções: o salário por peça.

Essa forma de pagamento possibilita a qualquer momento o aumento do ritmo e intensidade e o alongamento das jornadas de trabalho, pois como vimos, a remuneração conseguida pelos trabalhadores é insuficiente para a reprodução de força de trabalho. Assim, os trabalhadores tendem a intensificar o ritmo de produção na tentativa de conseguirem um rendimento mais elevado. Esta tentativa a longo prazo tende a rebaixar os salários gerais, pois o tempo de trabalho socialmente necessário acaba sendo reduzido.

Tavares e Lima (2009) expressam a relação do salário pago por peça e a intensificação do trabalho por meio de uma elevaçấo do ritmo e velocidade em jornadas de trabalho "estáveis". As autoras, ao estudarem o trabalho dos cortadores de cana, explicitam:

A jornada de trabalho para o cortador de cana, aprovada em dissídio coletivo, desde 1984, é de oito horas [...] Só recentemente, quando a precariedade do trabalho, aliada às denúncias de morte por exaustão, suscitou nas usinas o medo de penalidades, estas começaram a considerar a necessidade de respeitar a jornada legal de trabalho. Importa ressaltar que até agora a produtividade não foi reduzida. Ora, se a produção não diminuiu, duas hipóteses podem ser aventadas: ou a jornada de oitos horas não está sendo respeitada; ou o trabalho foi intensifi- 
cado, alterando-se, portanto, o tempo de trabalho socialmente necessário. Nesse contexto, chama a atenção o fato de cortadores de cana expressarem insatisfaçôes com uma lei que teoricamente objetiva protegê-los (informação verbal). Protegeria, não fosse a alternativa do salário por produção, da qual o capitalista dispóe. Essa modalidade de salário que pressiona o trabalhador nos mais diversos aspectos [...] (TAVARES; LIMA, 2009, p. 175, grifos nossos).

As autoras exemplificam a condição a partir de um processo de trabalho que "tem" uma jornada de trabalho constante de oito horas, portanto, a forma de ampliação da extração de mais-valia se deu pela intensificação do trabalho por meio do pagamento do salário por produção, que no trabalho do corte de cana já resultou em casos de morte por exaustáo, expressáo nítida da violação do fundo de vida dos trabalhadores (TAVARES; LIMA, 2009). Por isso, o pagamento por peça/produção atua no sentido de intensificar o trabalho, repercutindo na saúde dos trabalhadores de diferentes maneiras, e tem como expressôes mais agudas o aumento dos acidentes de trabalho ou o adoecimento biopsíquico dos trabalhadores.

O setor nacional de confecçóes também passou por modificaçóes que aumentaram sua produtividade, sobretudo com a aquisição de tecnologias que possibilitaram esta elevação. Porém, este incremento de produtividade ficou restrito a grandes empresas e associado a ele houve uma grande expansão das pequenas e microempresas nascidas nas precárias condições e relações de trabalho (JINKINGS; AMORIM, 2006). Esta dinâmica favorece alteraçóes no tempo de trabalho socialmente necessário à produção de mercadorias, visto que nas empresas que possuem uma produtividade mais elevada este tempo tende a diminuir, já nas "empresas" que possuem menor produtividade este tempo é mais elevado. Para compensar as diferenças entre a produção e apropriação do valor, é necessário lançar mão de instrumentos de intensificação, alongamento das jornadas e a remuneração da força de trabalho abaixo de seu valor.

Assim, compreendemos que nos municípios estudados as formas de superexploração da força de trabalho atuam de maneira articulada, seja nas variaçôes na duração da jornada de trabalho, na intensidade do trabalho e na remuneração da força de trabalho abaixo de seu valor.

\section{Considerações finais}

Nosso estudo concluiu que a dinâmica do APL de confecções segue as mudanças contemporâneas do mundo do trabalho. A flexibilização e a precarização do trabalho 
expressam-se na alta taxa de informalidade, nas condiçôes precárias de trabalho e na organização e gestáo da força de trabalho baseada no pagamento por peça/produção.

A aparente autonomia da produção é marcada por um forte discurso ideológico. No entanto, a estrutura e a dinâmica da relação expóem um limitado controle sobre a produção por parte dos trabalhadores, caracterizando uma relação assalariada "disfarçada" sob a ideologia do "empreendedorismo". A informalidade não atua enquanto "resíduo intersticial" a atividades que não são ocupadas pelas empresas capitalistas formais, pelo contrário, participa da produção de mercadorias, inclusive com articulação durante o desenvolvimento do processo de produção e distribuição, de atividades formais com as informais. A funcionalidade da informalidade está essencialmente relacionada à exteriorização das atividades das empresas para as facçooes, à redução de custos, à expansão de condiçóes precárias de trabalho e ao favorecimento da superexploração da força de trabalho.

O que se identificou no estudo como predominante foi que os trabalhadores se encontram-em situação de desproteção social, não têm acesso a direitos trabalhistas e previdenciários. A assistência social fica quase restrita ao recebimento do programa Bolsa Família e a renda oriunda deste cumpre importante papel na reprodução da força de trabalho. A tendência observada é a presença dos mecanismos de superexploração da força de trabalho para o conjunto de trabalhadores envolvidos na produção de vestuário nas facções.

Identificamos a articulação das formas de manifestação da superexploração da força de trabalho. Na nossa pesquisa, os trabalhadores são remunerados abaixo do valor de sua força de trabalho, essa remuneração é variável e sofre oscilaçôes durante meses do ano. Ainda foi possível explicitar que existe uma elevação do valor histórico moral da força de trabalho sem que este seja repassado aos trabalhadores, ou seja, o pagamento dos salários não acompanha as necessidades contemporâneas. Os gastos prioritários dos trabalhadores são com necessidades vitais, como alimentação, moradia e a manutenção das condiçôes de produção. Os gastos com a compra de água e, em alguns casos, com serviços particulares de saúde representam a transferência do fundo de consumo do trabalhador para a acumulação capitalista. Esses mecanismos atuam na violação do fundo de consumo dos trabalhadores.

Também constatamos os mecanismos de superexploração da força de trabalho expressos por meio da intensificação do trabalho e a extensão das jornadas. Estes mecanismos têm caráter relativo e estão relacionados à quantidade de peças 
encomendadas. O controle do trabalho é realizado pela forma de pagamento por peça/produção, e esta forma de pagamento modula tanto o ritmo e a velocidade do trabalho, intensificando-o, quanto o prolongamento da jornada. A manutenção desses mecanismos tende a violar o fundo de vida dos trabalhadores, esgotando a força de trabalho precocemente. ${ }^{5}$

\section{Referências}

ABRAMIDES, M. B. C.; CABRAL, M. S. R. Regime de acumulação flexível e saúde do trabalhador. São Paulo em Perspectiva, Sao Paulo, v. 1, n. 17, p. 3-10, jan. 2003.

ALVES, G. Precariedade e precarização do trabalho. In: . Dimensões da reestruturação produtiva: ensaios de sociologia do trabalho. 2. ed. Bauru: Práxis, 2007. p. 111-152.

ALVES, J. C. L.; JACKSON FILHO, J. M. Trabalho, saúde e formação política na enquete operária de Marx. Trabalho, Educação e Saúde, Rio de Janeiro, v. 15, n. 1, p. 13-31, jan./abr. 2017. AMARAL, A. S. do. Precarização estrutural e exploração da força de trabalho: tendências contemporâneas. Argumentum, Vitória, v. 10, n. 3, p. 244-256, set./dez. 2018.

AMARAL, A. S. do; MACEDO, R. S. Qualificação dos Trabalhadores no Arranjo Produtivo Local de Toritama: o papel do Estado e dos agentes privados. [S.I.], 2011. p. 1-11. Disponível em: <http:/www.estudosdotrabalho.org/texto/gt8/qualificacao.pdf>. Acesso em: 23 mar. 2018. ANTUNES, R. Os sentidos do trabalho: ensaios sobre a afirmação e a negação do trabalho. 2. ed. São Paulo: Boitempo Editorial, 2009. 285 p.

ARAUJO, C. A. L.; PEREIRA, C. F. A indústria de confecçóes em Pernambuco: impactos e oportunidades em um cenário pós-ATC (Acordo sobre Têxteis e Confecçôes). In: SIMPEP, 13., 2006, Bauru. Anais... Bauru: Simpep, 2006. p. 1-13.

BRASIL. Ministério da Fazenda. Anuário Estatístico da Previdência Social 2016. Brasília: Dataprev, 2016.

CABREIRA, L. F.; WOLFF, S. Precarização e informalidade na indústria de confecçóes em Cianorte (PR): crise na tutela trabalhista. In: NAVARRO, V. L.; LOURENÇO, E. A. S. (Org.). $O$ avesso do trabalho III: saúde do trabalhador e questóes contemporâneas. São Paulo: Expressão Popular, 2013. p. 199-218.

CARVALHO, C. B. R. P.; SILVA, S. R. A. (Org.). Diálogo social: mulheres costurando direitos. Santa Cruz do Capibaribe: Secretaria da Mulher de Pernambuco, 2015. 84 p.

DAL ROSSO, S. O ardil da flexibilidade: os trabalhadores e a teoria do valor. São Paulo: Boitempo Editorial, 2017. 286 p. 
DAL ROSSO, S. Ondas de intensificação do labor e crise. Perspectivas, São Paulo, v. 39, n. 1, p. 133-154, jan./jun. 2011.

DAL ROSSO, S. Mais trabalho! A intensificação do labor na sociedade contemporânea. São Paulo: Boitempo Editorial, 2008. $206 \mathrm{p}$

DIEESE. Pesquisa Nacional da Cesta Básica de Alimentos: salário mínimo nominal e necessário. 2018. Disponível em: <https://www.dieese.org.br/analisecestabasica/salarioMinimo. html\#2017>. Acesso em: 22 mar. 2018.

DRUCK, G. Precarização e Informalidade: algumas especificidades do caso brasileiro. In: OLIVEIRA, R. V.; GOMES, D; TARGINO, I. Marchas e contramarchas da informalidade do trabalho: das origens às novas abordagens. João Pessoa: Editora Universitária Ufpb, 2011. p. 65-103.

DRUCK, G. A metamorfose da precarização social do trabalho. Margem à Esquerda, São Paulo, v. 1, n. 18, p.37-41, jun. 2012.

INSTITUTO BRASILEIRO DE GEOGRAFIA E ESTATÍSTICA. Pesquisa Nacional por Amostra de Domicílios Contínua: rendimento de todas as fontes 2017. Rio de Janeiro: [s.i], 2018. 8 p. JC ONLINE (Pernambuco). Agreste Empreendedor: Polo de Confecções. 2017. Disponível em: $<$ http://especiais.jconline.ne10.uol.com.br/agresteempreendedor/polo-de-confeccoes/>. Acesso em: 12 mar. 2018.

JINKINGS, I.; AMORIM, E. R. A. Produção e desregulamentação na indústria têxtil e de confecção. In: ANTUNES, Ricardo (Org.). Riqueza e miséria do trabalho no Brasil. São Paulo: Boitempo Editorial, 2006. p. 337-385.

KOSIK, K. Dialética do concreto. 2. ed. Rio de Janeiro: Paz e Terra, 1976. 230 p

LACERDA, A. Agreste tem $2^{\circ}$ maior polo têxtil do País. 2013. Disponível em: <http://economia. estadao.com.br/noticias/geral,agreste-tem-2-maior-polo-textil-do-pais-imp-,981078>. Acesso em: 21 jan. 2018.

LAURELl, Asa Cristina; NORIEGA, Mariano. Processo de Produção e Saúde: Trabalho e Desgaste Operário. São Paulo: Hucitec, 1989. 333 p.

LIRA, S. M. Os aglomerados de micro e pequenas indústrias de confecçóes do Agreste-PE: um espaço construído na luta pela sobrevivência. Revista de Geografia. Recife, v. 23, n. 1, p. 98-114, jan. 2006.

LUCE, M. S. A superexploração da força de trabalho no Brasil. Soc. Bras. Economia Política, São Paulo, v. 1, n. 32, p. 119-141, 2012.

. A superexploração da força de trabalho. In: . Teoria marxista da dependência: problemas e categoriais. Uma visão histórica. São Paulo: Expressão Popular, 2018. p. 135-196.

. Brasil: nova classe média ou novas formas de superexploração da força de trabalho? Trabalho, Educação e Saúde, Rio de Janeiro, v. 11, n. 1, p. 169-190, jan./abr. 2013. 
MACEDO, R. S.; AMARAL, A. S. Os fundamentos teóricos e políticos que orientam a relação trabalho-educação no Arranjo Produtivo Local (APL) de Confecçóes do Agreste de Pernambuco. [S.I], 2013. p. 1 - 22.

MARINI, R. M. Dialética da dependência. In: TRASPADINI, R.; STEDILE, J. P. Ruy Mauro Marini: vida e obra. 2. ed. São Paulo: Expressão Popular, 2011. p. 131-172.

MARX, K. O capital: Livro I. São Paulo: Boitempo Editorial, 2013. 894 p.

MINAYO-GOMEZ, C.; THEDIM-COSTA, S. M. F. A construção do campo da saúde do trabalhador: percurso e dilemas. Cad. Saúde Públ, Rio de Janeiro, v. 2, n. 15, p. 21-32, jan. 1997. MOTA, A. E.; PERUZZO, J. F. Trabalho precário e superexploração na indústria do vestuário em Pernambuco. In: Encontro Nacional de Economia Política, XX. Anais... 2015.

PIMENTEL, T. Diário de Pernambuco. Santa Cruz é sinônimo de polo têxtil. 2017. Disponível em: <http://www.impresso.diariodepernambuco.com.br/app/noticia/cadernos/ economia/2017/01/14/interna_economia,161460/santa-cruz-e-sinonimo-de-polo-textil.shtml>. Acesso em: 22 mar. 2018.

RODRIGUES, H. C. P. Trabalho e Assistência Social: Bolsa Família e reprodução da força de trabalho no município de Toritama-PE. In: MOTA, A. E. (Org.). As ideologias da contrarreforma e o Serviço Social. Recife: Ed. Universitária Ufpe, 2010. p. 243-284.

SAMAJA, J. Muestras y representatividad en vigilancia epidemiologica mediante sitios centinelas. Cad. Saúde Pública, Rio de Janeiro, v. 3, n. 12, p.309-319, jul./set. 1996.

SANTOS, J. B. F.; OSTERNE, M. S. F.; ALMEIDA, R. O. A entrevista como técnica de pesquisa do mundo do trabalho. In: ALVES, G.; SANTOS, J. B. F. Métodos e técnicas de pesquisa sobre o mundo do trabalho. Bauru: Práxis, 2014. p. 29-52.

SILVA, J. A. R. O. A flexibilização da jornada de trabalho e seus reflexos na saúde do trabalhador. In: NAVARRO, V. L.; LOURENÇO, E. A. S. (Org.). O avesso do trabalho III: saúde do trabalhador e questóes contemporâneas. São Paulo: Expressão Popular, 2013. p. 61-90. SEBRAE (Pernambuco). Estudo Econômico do Arranjo Produtivo Local de Confecçóes do Agreste Pernambucano 2012. Recife: \{s.i\}, 2013.

SOUZA, D. O.; MELO, A. I. S. C.; VASCONCELLOS, L. C. Saúde do(s) trabalhador(es): do "campo" à "questáo" ou do sujeito sanitário ao sujeito revolucionário. Saúde e Debate, Rio de Janeiro, v. 41, n. 113, p. 591-604, abr./jun. 2017.

TAVARES, M. A.; LIMA, R. O. T. A "liberdade" do trabalho e as armadilhas do salário por peça. Revista Katálysis, Florianópolis, v. 12, n. 2, p. 170-177, jul./dez. 2009. 


\section{Notas}

${ }^{1} \mathrm{O}$ termo façonismo ou facção equivale à expressão à façon do francês, significando "um sistema de trabalho correspondente à simples prestação de serviços” (COLI, 2000 apud TAVARES, 2004, p. 187).

${ }^{2}$ Lembramos que o salário mínimo no período de realização das entrevistas estava estipulado em $\mathrm{R} \$$ 937,00.

${ }^{3}$ Segundo Luce (2018, p. 180), "para calcular o SMN, o Dieese produz o levantamento do preço médio de 13 produtos alimentares que constam no Decreto-lei no 399/1938 e nas quantidades especificadas por este. Depois, é calculado o gasto mensal agregado de cada um dos produtos. Considerando a unidade familiar típica composta em média por dois adultos e duas crianças e o consumo de uma criança como equivalente à metade de um adulto, multiplica-se por três o preço mensal da cesta básica do Dieese, e o resultado é novamente multiplicado, agora pelo peso da inflação na porcentagem que a alimentação representa entre os gastos essenciais de uma família no rol dos demais itens avaliados pelo Índice do Custo de Vida (ICV) e que entram também na cesta de consumo do SMN. Com base nesse resultado, produz-se a série histórica a preços correntes do ano levando em consideraçấo a evolução, buscando traçar a evoluçáo do poder de compra do salário mínimo legal em relação à quantidade e aos tipos de valores de uso reconhecidos como necessários para um trabalhador ou trabalhador sustentar a si e a família".

${ }^{4}$ O estrato da "Classe C" tinha remuneração entre R \$ 906 a R \$ 2.200 (dados de 2012). Como o autor pontua, valor inferior ao salário mínimo necessário para o período (LUCE, 2018).

${ }^{5}$ P. V. R. de A. Lira participou de todas etapas da pesquisa, da elaboração e revisão do artigo. I. G. D. Gurgel orientou a pesquisa e participou da construção dos resultados, discussão e revisão final do artigo. A. S. do Amaral coorientou a pesquisa e participou da construção dos resultados, discussão e revisão final do artigo. 


\section{Abstract}

\section{Overexploitation of the workforce and workers' health: precarious work in clothing making}

Understanding the changes in the world of work and how they relate to the health-disease process is essential. This study aimed to analyze the expressions of the overexploitation of the workforce and its impact on the health of workers from faç̧ôes in two municipalities in the local production arrangement of the Agreste in Pernambuco state, Brazil. The research was guided by a perspective that considers the totality and historicity of social relations and their articulation with particular social processes. Questionnaires and semi-structured interviews were applied to confection workers in the municipalities of Toritama and Santa Cruz do Capibaribe, in 2017. The results were analyzed based on the dialectic method. The overexploitation of the workforce was expressed in labor relations through the articulation of the workforce's remuneration below its value, the increase in the historical moral value of the workforce without its corresponding payment, the extension of working hours and the intensification of the work carried out in the faç̧oes. Such characteristics tend to violate the consumption and life fund of workers, who may present an early strain on their workforce, which can be evidenced by illness and / or early loss of ability to work.

> Keywords: worker's health; work precarization; workrelated diseases. 